\title{
Role of Nonbehavioral Factors in Adjusting Long Bone Diaphyseal Structure in Free-ranging Pan troglodytes
}

\author{
K. J. Carlson • D. R. Sumner • M. E. Morbeck • \\ T. Nishida • A. Yamanaka $\cdot$ C. Boesch
}

Received: 19 April 2007 / Accepted: 7 July 2008 /

Published online: 18 October 2008

(C) Springer Science + Business Media, LLC 2008

\begin{abstract}
Limb bones deform during locomotion and can resist the deformations by adjusting their shapes. For example, a tubular-shaped diaphysis best resists variablyoriented deformations. As behavioral profiles change during adulthood, patterns of bone deformation may exhibit age trends. Habitat characteristics, e.g., annual rainfall, tree density, and elevation changes, may influence bone deformations by eliciting individual components of behavioral repertoires and suppressing others, or by influencing movements during particular components. Habituated chimpanzee communities provide a unique opportunity to examine these factors because of the availability of morphological data and behavioral observations from known-age individuals inhabiting natural habitats. We evaluated adult femora and humeri of 18 female and 10 male free-ranging chimpanzees (Pan troglodytes) from communities
\end{abstract}

K. J. Carlson $(\bowtie)$

Department of Anatomy, New York College of Osteopathic Medicine, Old Westbury,

NY 11568-8000, USA

e-mail:kcarlson@nyit.edu

D. R. Sumner

Department of Anatomy and Cell Biology, Rush Medical College, Chicago, IL 60612, USA

\section{E. Morbeck}

Departments of Anthropology and Cell Biology and Anatomy, University of Arizona, Tucson, AZ 85721-0030, USA

T. Nishida

Mahale Mountains Chimpanzee Research Project, Graduate School of Science, Kyoto University, Kyoto 606-8502, Japan

\author{
A. Yamanaka \\ Department of Oral Anatomy, Kagoshima University Dental School, Kagoshima 890-8580, Japan \\ C. Boesch \\ Max-Planck Institute for Evolutionary Anthropology, 04103 Leipzig, Germany
}


in Gombe (Tanzania), Mahale Mountains (Tanzania), and Taï Forest (Côte d'Ivoire) National Parks. We compare cross sections at several locations (35\%, 50\%, 65\% diaphyseal lengths). Community comparisons highlight different diaphyseal shapes of Taï females relative to Mahale and Gombe females, particularly in humeral diaphyses. Age trends in diaphyseal shapes are consistent with reduced activity levels in general, not only reduced arboreal activity. Age-related bone loss is apparent among community females, but is less striking among males. Community trends in diaphyseal shape are qualitatively consistent with ranked annual rainfall at localities, tree density, and elevation change or ruggedness of terrain. Habitat characteristics may contribute to variation in diaphyseal shape among chimpanzee communities, much like among modern human groups, but verification awaits further rigorous experimental and comparative analyses.

Keywords aging $\cdot$ Gombe $\cdot$ locomotor behavior $\cdot$ Mahale $\cdot$ Pan troglodytes $\cdot$ Taï

Chimpanzees (Pan troglodytes) offer a unique opportunity to address functional morphological questions in the primate postcranium. Chimpanzees are the most appropriate referential model among living species for modeling locomotor repertoires of early hominins (Moore 1996; Zihlman 1996). Long-term observational studies of free-ranging chimpanzee communities provide a detailed portrait of their life histories (Boesch and Boesch-Achermann 2000; Goodall 1986; Morbeck 1999; Nishida 1990). For example, behavioral studies over the last $45 \mathrm{yr}$ at Gombe Stream National Reserve (Tanzania), Mahale Mountains National Park (Tanzania), and Taï Forest National Park (Côte d'Ivoire) documented activity profiles for female and male chimpanzees of all ages. During that time, investigators prudently accumulated skeletal remains from individuals of the communities when possible. Thus, specimens from the communities comprise a truly exclusive sample of free-ranging individuals for which both a behavioral repertoire and life history are often available.

Locomotor behavior requires an individual to interact dynamically with the environment (Prost 1965), and as such, it fulfills a critical requirement for eliciting bone functional adaptations (Ruff et al. 2006; Turner 1998). Bone functional adaptations in the postcranial skeleton are the result of mechanotransduction of deformations in bones, i.e., osseous responses to deformations in vivo arising during dynamic behaviors, such as quadrupedalism, climbing, scrambling. Though discussion continues over whether the sequence of events is load frequency or load magnitude driven, it is clear that bone mechanotransduction operates on a cellular level via modeling and remodeling phenomena (Burr et al. 2002; Currey 2002; Frost 2001; Martin et al. 1998; Rubin et al. 2006; Umemura et al. 1997). Bone mineral content changes in response to dynamic locomotor characteristics (Hurwitz et al. 1998; Moisio et al. 2004). Factors other than deformations resulting from dynamic behaviors can interject an influence on the processes (Martin et al. 1998; Pearson and Lieberman 2004). Mechanotransduction, and hence bone structural properties, have heritable components (Robling et al. 2007; Turner et al. 2000; Wergedal et al. 2005; Xiong et al. 2006). Bone modeling rates slow into adulthood, with a drop after the cessation of prepubertal growth, and human females are more at risk than males for losing bone mass later in adult life history (Martin et al. 1998). Even though 
bone modeling rates slow over adulthood, bone retains a limited capacity to sculpt diaphyseal shape via cortical drift and Haversian remodeling, i.e., coupled bone resorption and formation. Thus, when bone deformation does not exceed minimal bone maintenance thresholds, e.g., during reduced activity levels, net bone resorption will occur (Frost 2001). Selective resorption of bone mass during such periods of reduced mechanical loading, e.g., depressed activity levels, theoretically may adjust chimpanzee diaphyseal shapes, in part, according to behavioral changes occurring during advanced stages of adulthood.

Cross-sectional geometric properties offer a potentially useful means to compare functionally relevant skeletal differences among populations. Numerous studies have applied the approach to the limb bones of human and nonhuman primates (Burr et al. 1982, 1989; Carlson 2002, 2005; Carlson et al. 2006; Demes and Jungers 1989, 1993; Demes et al. 1991; Jungers et al. 1998, Ohman 1993; Polk et al. 2000; Ruff 1987, 1989, 2002; Ruff and Runestad 1992; Schaffler et al. 1985; Sumner and Andriacchi 1996; Terranova 1995a, b; Yamanaka et al. 2005). Experimental studies of bone deformation during locomotion demonstrate the need for caution when inferring locomotor performance from cross-sectional properties alone (Demes et al. 1998, 2001; Lieberman et al. 2004). In these experimental studies, the distribution of bone in a diaphyseal cross section exhibited nonoptimal distributions for minimizing recorded bone deformation during peak strains associated with the investigated behaviors. Documenting bone strain, e.g., peak strains and strain gradients, during additional components of primate locomotor repertoires would be useful to refine further the extent of these cautions.

African apes exhibit shape variations in their femoral and humeral diaphyses that at several locations are associated with reported frequencies of arboreal locomotion (Carlson 2002, 2005). Carlson (2002, 2005) correlated more evenly distributed bone mass in a cross section, i.e., more circular shape, with increased percentage of arboreal locomotion at multiple femoral and humeral diaphyseal locations. In primate bone strain studies, Demes et al. (2001) and Swartz et al. (1989) reported greater variation in load orientations experienced by limb bones during select modes of an arboreal locomotor repertoire, i.e., vertical climbing and brachiation, respectively, relative to quadrupedal walking on terrestrial substrates, which lends intuitive support to the notion that bone cross sections experiencing more variable load orientations configure a more circular distribution to resist deformations from multiple orientations. However, researchers have not linked frequencies of specific locomotor behaviors, vs. arboreal locomotion in general, to specific diaphyseal shapes in any straightforward fashion (Carlson 2005). The relationships become difficult to assess in museum collections, where behavioral repertoires and life histories of individuals are unknown, but even when investigating a small sample of free-ranging chimpanzees $(n=7)$ for which morphological, behavioral frequency, and life history data are available, individual locomotor mode frequencies do not exhibit consistent relationships to specific diaphyseal shapes (Carlson et al. 2006).

Given the possibility that variability within loads associated with specific locomotor modes may obscure mode-specific links in bone cross-sectional shapes, we investigated nonbehavioral contributions to such potential variability. Gombe chimpanzees adjust locomotor repertoires as a consequence of aging by limiting travel and climbing behavior with age (Goodall 1986; Morbeck et al. 2002). The 
latter observation may partly reflect relatively high energetic demands associated with vertical climbing (Pontzer and Wrangham 2004). Demes et al. (2001) anecdotally noted that climbing behavior had more variable strain orientations vs. orientations observed during terrestrial quadrupedalism in macaques. Because bone deformations resulting from loading can be site-specific (Gross et al. 1997; Judex et al. 1997), net resorptive remodeling resulting from local strain magnitudes below bone maintenance thresholds may result in specific diaphyseal shape changes associated with behavioral changes during later stages of adulthood. Older chimpanzees climbing with decreasing frequency may exhibit altered shape or cross-sectional properties in their limb bones concordantly.

Habitat characteristics are another potential contributing factor to variability in loads. Chimpanzees occupying more open habitats, e.g., Mt. Assirik, Senegal and Toro-Semliki Wildlife Reserve, Uganda, exhibit higher percentages of terrestrial locomotion within locomotor repertoires than chimpanzees occupying more closed habitats, e.g., Taï Forest National Park (Hunt and McGrew 2002). In addition to locomotor profile differences, open habitat chimpanzees typically travel further in a given day than chimpanzees occupying more closed habitats (Hunt and McGrew 2002). Qualitative differences within quadrupedalism ultimately could impact deformation patterns experienced by limb elements. Mobility adaptations in diaphyseal shapes, in part, could reflect the prevalence of obstacles in a landscape, e.g., vegetation density or ground cover. Individuals with equivalent frequencies of quadrupedal locomotion, but that differ in turning frequency, may differ in diaphyseal shapes according to turn frequency, e.g., mediolateral rigidity increases as turning frequency increases.

Elevational changes and ruggedness of terrain are two additional ecogeographic factors that could influence deformations experienced by long bone diaphyses (Ruff 1999). Burr et al. (1996) demonstrated higher local strain magnitudes in human tibiae during travel on inclined or declined surfaces relative to level surfaces. Habitat characteristics may influence structural properties of long bone diaphyses from habituated chimpanzee communities in a similar manner.

With a sample of free-ranging adult chimpanzees from the 3 communities, we addressed several questions concerning bone functional adaptations in chimpanzee postcranial skeletons. 1) Do femoral and humeral diaphyseal shapes vary among the 3 chimpanzee communities? If so, are there observable patterns in this variation, including female vs. male differences? 2) Do diaphyseal shapes or percent cortical areas $(\% \mathrm{CA})$ change over the course of adulthood in the chimpanzee communities, and do females vs. males differ in this regard? 3) Do habitat characteristics of the three chimpanzee communities offer insight into any observed variation in their diaphyseal cross-sectional shapes or \%CAs?

\section{Materials and Methods}

Using computed tomography (CT), we scanned humeri and femora of 18 adult female and 10 adult male chimpanzees (Pan troglodytes) from Gombe (Tanzania), Mahale Mountains (Tanzania), and Taï Forest (Côte d'Ivoire) National Parks to acquire cross-sectional images equivalent to 3 locations per diaphysis: 35\% (mid-distal), 
50\% (midshaft), and 65\% (mid-proximal) diaphyseal lengths (Table I). Several Taï individuals in the sample died as a result of an Ebola epidemic (Boesch and BoeschAchermann 2000). We excluded only individuals with serious injuries or long-term diseases that could have permanently altered locomotor repertoires. The CT scanning protocols for Gombe and Mahale specimens follow previously described methods (Carlson et al. 2006; Sumner et al. 1989; Yamanaka et al. 2005).

We acquired data from Taï chimpanzees also via CT scans, but with slight differences in methodology. For Taï specimens, we obtained serial images from entire sets of long bones. We saved images in DICOM format, which is the standard file format in medical imaging. We imported image stacks corresponding to entire long bones into commercially available visualization software, e.g., Amira ${ }^{\circledR}$; segmented the stacks to create isosurfaces; and then visualized surfaces of volumes of interest (VOIs) via thresholds that gave an accurate representation of surface appearance. We chose a threshold while considering two criteria: elimination of artificial holes in continuous surfaces vs. exclusion of lower density objects from

Table I Sample

\begin{tabular}{|c|c|c|c|c|}
\hline & Individual & Sex & Age & Elements \\
\hline \multirow[t]{9}{*}{ Gombe } & Flo & Female & 43 & Left femur, left humerus \\
\hline & Miff & Female & 31 & Left femur, left humerus \\
\hline & Old Female & Female & 40 & Left femur, left humerus \\
\hline & Pallas & Female & 27 & Left femur, left humerus \\
\hline & Passion & Female & 31 & Left femur, left humerus \\
\hline & Charlie & Male & 26 & Left femur, left humerus \\
\hline & Hugo & Male & 39 & Left humerus \\
\hline & Jomeo & Male & 31 & Left femur, left humerus \\
\hline & Satan & Male & 32 & Left humerus \\
\hline \multirow[t]{4}{*}{ Mahale $^{\mathrm{a}}$} & Betty & Female & 20 & Both femora, left humerus \\
\hline & Pulin & Female & 23 & Both femora, both humeri \\
\hline & Wansombo & Female & 41.5 & Both femora, both humeri \\
\hline & Musa & Male & 36 & Both femora, both humeri \\
\hline \multirow[t]{15}{*}{ Taï } & Agathe & Female & 15 & Both femora, both humeri \\
\hline & Bijou & Female & 19 & Right femora, both humeri \\
\hline & Fanny & Female & 25 & Both femora \\
\hline & Kiri & Female & 23 & Both femora, both humeri \\
\hline & Ondine & Female & 38 & Both femora, both humeri \\
\hline & Tita & Female & 25 & Both femora, left humerus \\
\hline & Fitz & Male & 19 & Left femur \\
\hline & Kendo & Male & 25 & Both femora, both humeri \\
\hline & Macho & Male & $(36)^{c}$ & Left femur, both humeri \\
\hline & Unknown 1 & Female & - & Both femora, both humeri \\
\hline & Unknown 2 & Female & - & Both femora, both humeri \\
\hline & Unknown 3 & Female & - & Left femur, both humeri \\
\hline & Unknown 4 & Female & - & Both humeri \\
\hline & Unknown 5 & Male & - & Both femora, left humerus \\
\hline & Unknown 6 & Male & - & Both femora \\
\hline
\end{tabular}

\footnotetext{
${ }^{\text {a }}$ Sample demographics reported in Hosaka et al. (2000).

${ }^{\mathrm{b}}$ Sample demographics reported in Boesch and Boesch-Achermann (2000).

${ }^{\mathrm{c}}$ Attribution of postcranial elements to Macho is contended (Zihlman, personal communication). Age at death is estimated for Macho, and is likely $\leq 2 \mathrm{yr}$ from this estimate (i.e., 34-38 yr) due to the date of collection and the absence of a death date reported by Boesch and Boesch-Achermann (2000).
} 
the bone surface, e.g., desiccated soft tissues or residual foreign objects. Appropriate thresholds routinely varied little between the bones following these criteria. After identifying an appropriate threshold, we saved a segmented isosurface as a separate digital VOI. Thus, each VOI represented a skeletal element. After producing digital replicas of bones, we performed subsequent analysis via both commercially available software (Amira ${ }^{B}$ ) and custom-written software (FoRM-IT: Zollikofer et al. 1995). Each software option has its own benefits, but commercial software $\left(\right.$ Amira $\left.^{\circledR}\right)$ is sufficient for the aforementioned purpose and is more widely available.

We aligned VOIs in virtual space via the same criteria for positioning physical specimens in CT scanners (Carlson 2005; Ruff 2002). We acquired length dimensions of aligned VOIs to identify regions of interest (ROIs): 35\%, 50\%, and $65 \%$ diaphyses. Once we located ROIs, we used cutting planes to virtually section VOIs. We used screen capture software programs, or options within the visualization software, to generate a digital image of a virtually sectioned surface, i.e., a cross section. Our method has an advantage over using CT images directly because the virtual cross section represents a surface, i.e., no $z$-dimension, instead of a slice of bone that has a given thickness. When digitizing the estimated cross-sectional area, eliminating thickness removes potential error in the digitized estimates of crosssectional area that could result from bone curvature artificially expanding external or internal bone-air boundaries, i.e., error created by collapsing a $3 \mathrm{D}$ slice into a $2 \mathrm{D}$ representation during manual or automated edge-detection.

After virtually sectioning Taï VOIs, we analyzed cross sections of chimpanzee femora and humeri from all 3 communities via the same procedure. For approximately half of all cross sections in the Taï sample, we calculated crosssectional properties using both virtual replicas of cross sections and single-slice CT images at comparable diaphyseal ROIs. Mean shape $\left(I_{\max } / I_{\min }\right)$ for ROIs $(n=66)$ using the virtual-based method is $1.376(1 \mathrm{SD}=0.193)$ and for the single-slice method (Carlson 2005; Carlson et al. 2006) it is 1.382 (1 $\mathrm{SD}=0.197)$. Mean percentage cortical area $(\% \mathrm{CA})$ for ROIs $(n=66)$ via the described virtual-based method is $65.27(1 \mathrm{SD}=6.06)$ and for the single-slice method it is $62.01(1 \mathrm{SD}=$ $6.43)$. The difference in mean shape ratio and \%CA using the 2 procedures is well within 1 SD. Different threshold selection criteria may contribute to the small observed distinctions between the averages, particularly \%CA.

We calculated cross-sectional geometric properties at diaphyseal ROIs via custom-written macros for Scion Image (release Beta 4.0.2; ported from NIH Image for Macintosh by Scion Corporation and freely available at http://www.scioncorp. com) and a modified version of SLICE (Nagurka and Hayes 1980). We calculated shape ratios as $I_{\max } / I_{\min }$ instead of $I_{x} / I_{y}$ because the former ratio provides a more accurate reflection of shape differences than the latter ratio (Carlson 2005). We considered cortical bone as homogeneous in material properties, as is customary in analyses of cross-sectional properties ( $c f$. Bhatavadekar et al. 2006). We use percentage cortical area (\%CA), which we calculate as cortical area (CA) divided by total area (TA). Because $I_{\max } / I_{\min }$ and $\% \mathrm{CA}$ are ratios, it is unnecessary to normalize them to size, which is advantageous because few of the subjects have associated body mass data.

In quantifying \%CA, we followed Sumner et al. (1989), who demonstrated among Gombe chimpanzees increased subperiosteal bone deposition and endosteal 
resorption of bone during aging. Sumner et al. (1989) observed a net decrease in \% CA, which likely resulted from slower deposition rates at the subperiosteal envelope relative to resorption rates at the endosteal envelope. Quantifying and comparing bone mass more precisely than using \%CA requires data on bone quality, i.e., mineral content, which was unavailable from much of the sample.

We compiled habitat characteristics of Gombe, Mahale, and Taï National Parks from published reports (Table II). We selected specific characteristics that we believe are relevant to several factors: the extent of arboreal locomotion, estimates of obstacles encountered during quadrupedalism, and the extent of terrestrial locomotion occurring over uneven terrain. We recognize that additional characteristics may affect chimpanzee bone functional adaptations.

We used Kolmogorov-Smirnov tests for normality to assess shape ratio and \%CA distributions. Kolmogorov-Smirnov tests compare observed to theoretical distributions, which in this case was the normal distribution. Because distributions of shape ratio or $\% \mathrm{CA}$ rarely depart from normality, and because sample sizes usually were not exceedingly small, e.g., $n \geq 4$, we used parametric instead of nonparametric tests because of greater statistical power of the former.

We used one-way ANOVAs to assess whether diaphyseal shapes of Gombe, Mahale, and Taï populations differed significantly. We used a Levene test for homogeneity of variances to test the assumption of equal variances across communities. When we observed a significant ANOVA test statistic and a nonsignificant Levene statistic, i.e., group variances were not significantly different, we performed Bonferroni analyses post hoc to distinguish which groups differed significantly. We chose Bonferroni post hoc analyses rather than other available options because Bonferroni tests adjust observed significance levels for multiple comparisons. When we observed both a significant ANOVA test statistic and a significant Levene statistic, i.e., group variances were significantly different, we conducted Tamhane's T2 post hoc analyses to distinguish which groups differed significantly. A Tamhane's T2 post hoc analysis is based on a $t$-test, and we prefer it to alternatives because it is conservative. Right elements were available from only Mahale and Taï communities, so we used $t$-tests instead of ANOVAs to assess differences in diaphyseal shapes for right ROIs.

Table II Habitat characteristics of habituated groups

\begin{tabular}{llll}
\hline & Gombe $^{\mathrm{a}}$ & Mahale $^{\mathrm{b}}$ & Tai $^{\mathrm{c}}$ \\
\hline Annual rainfall & $1495 \mathrm{~mm}$ & $1805 \mathrm{~mm}^{\mathrm{d}}$ & $1830 \mathrm{~mm}$ \\
Ground cover & More open woodland & Closed forest, vine tangles (M-group) & Tropical moist forest \\
Elevational range & $772-1500 \mathrm{~m}$ & $772-2462 \mathrm{~m}$ & About $120 \mathrm{~m}$ \\
Slope of terrain & 16.5 degrees & 8.3 degrees $^{e}$ & Slightly undulating \\
\hline
\end{tabular}

\footnotetext{
${ }^{a}$ Annual rainfall, elevation range, and slope of terrain reported by Collins and McGrew (1988); ground cover described by Hunt (1992).

${ }^{\mathrm{b}}$ Annual rainfall reported by Nishida (1990); ground cover described by Hunt (1992); elevation range and slope of terrain reported by Collins and McGrew (1988).

${ }^{\mathrm{c}}$ Annual rainfall reported by McGraw (1998); ground cover described by Martin (1991); elevation range and slope of terrain described by Boesch and Boesch-Achermann (2000).

d Averaged values of those at Kansyana Camp (1973-1988) and Myako Camp (1976-1984).

${ }^{\mathrm{e}}$ Averaged values for Kasoje: K1-K4, and reported as gradient (Collins and McGrew, 1988: Table I).
} 
Table III Community means (1 SD) for shape ratios $\left(I_{\max } / I_{\min }\right)$ and \% cortical area

\begin{tabular}{llllll}
\hline \multicolumn{7}{l}{ Females } & & & \\
\cline { 2 - 5 } ROI & Gombe (left) & Mahale (left) & Mahale (right) & Taï (left) & Taï (right) \\
\hline F35 shape & $1.38(0.21)$ & $1.30(0.05)$ & $1.29(0.04)$ & $1.48(0.09)$ & $1.53(0.14)$ \\
F50 shape & $1.45(0.17)$ & $1.29(0.09)$ & $1.33(0.10)$ & $1.47(0.09)$ & $1.53(0.14)$ \\
F65 shape & $1.43(0.09)$ & $1.42(0.16)$ & $1.40(0.16)$ & $1.45(0.15)$ & $1.51(0.09)$ \\
H35 shape & $1.24(0.09)$ & $1.25(0.02)$ & $1.21(0.04)$ & $1.14(0.09)$ & $1.15(0.09)$ \\
H50 shape & $1.13(0.07)$ & $1.19(0.06)$ & $1.16(0.01)$ & $1.38(0.12)$ & $1.40(0.09)$ \\
H65 shape & $1.08(0.04)$ & $1.15(0.12)$ & $1.10(0.03)$ & $1.29(0.14)$ & $1.35(0.15)$ \\
F35\%CA & $44.7(7.6)$ & $65.7(14.8)$ & $64.8(14.6)$ & $60.8(5.5)$ & $60.2(5.2)$ \\
F50\%CA & $48.1(9.8)$ & $71.7(15.9)$ & $70.3(16.3)$ & $66.4(5.3)$ & $65.7(4.8)$ \\
F65\%CA & $47.3(9.1)$ & $72.3(19.0)$ & $71.8(19.1)$ & $67.0(5.3)$ & $67.2(4.6)$ \\
H35\%CA & $42.3(9.4)$ & $67.9(16.6)$ & $63.2(20.4)$ & $63.8(8.3)$ & $64.3(6.0)$ \\
H50\%CA & $39.9(8.0)$ & $67.0(15.8)$ & $61.6(20.5)$ & $60.9(6.3)$ & $62.8(3.9)$ \\
H65\%CA & $37.9(6.2)$ & $63.3(16.8)$ & $58.8(23.3)$ & $60.8(8.7)$ & $61.9(6.4)$ \\
\hline F &
\end{tabular}

$\mathrm{F}=$ femur, $\mathrm{H}=$ humerus; 35 = mid-distal diaphysis, $50=$ midshaft, $65=$ mid-proximal diaphysis. Cells contain mean values and 1 standard deviation in parentheses. Rows represent values of shape $\left(I_{\max } / I_{\min }\right)$ or \%CA at a given ROI (e.g., F35). Gombe individuals are represented by left elements only.

We used Pearson correlation analyses to assess associations among shape, \%CA, and age. We restricted correlation analyses to left elements because right elements were not available from Gombe individuals.

We selected $p<0.05$ as the level of statistical significance for all statistical testing. We used SPSS 12.0.1 (SPSS Inc., Chicago) for statistical procedures.

\section{Results}

\section{Diaphyseal Shape Variation Among Community Females and Males}

Average values for shape ratios are separated by sex and side for each community in Table III. Taï females are different from both Gombe and Mahale females at multiple ROIs. Taï female chimpanzees exhibit statistically significant differences in shape from Gombe female chimpanzees at 2 humeral ROIs: the left humeral midshaft (H50) and left mid-proximal humeral diaphysis (H65) (Table IV). Taï female chimpanzees are significantly different from Mahale female chimpanzees at ROIs both in the femoral (right mid-distal, F35) and humeral diaphyses (right and left midshaft, H50) (Table IV). Differences between Taï and Mahale females approach statistical significance at 2 other ROIs: right femoral midshaft (F50: $p=0.051)$ and right mid-proximal humeral diaphysis $(\mathrm{H} 65: p=0.053)$. Mahale and Gombe females do not differ significantly in diaphyseal shape at left ROIs.

Significant shape differences among community males are less noticeable than the differences among females, possibly because of a smaller male sample (Table IV). Taï and Gombe males are not significantly different at any left ROIs. We avoided statistical evaluation of male shape differences at right ROIs because one of the two community subsamples, i.e., Mahale, includes only one specimen.

General qualitative comparisons of female and male averages in Table III, i.e., comparing visual trends in averages, supplement observed statistical trends. 


\begin{tabular}{llllll}
\hline \multicolumn{7}{l}{ Males } & & & \\
\cline { 2 - 6 } & Gombe (left) & Mahale (left) & Mahale (right) & Taï (left) & Taï (right) \\
\hline F35 shape & $1.38(0.17)$ & $1.34(-)$ & $1.34(-)$ & $1.53(0.08)$ & $1.51(0.14)$ \\
F50 shape & $1.39(0.16)$ & $1.34(-)$ & $1.42(-)$ & $1.50(0.08)$ & $1.55(0.23)$ \\
F65 shape & $1.39(0.21)$ & $1.37(-)$ & $1.31(-)$ & $1.37(0.11)$ & $1.45(0.03)$ \\
H35 shape & $1.30(0.12)$ & $1.23(-)$ & $1.17(-)$ & $1.11(0.06)$ & $1.22(0.17)$ \\
H50 shape & $1.10(0.02)$ & $1.17(-)$ & $1.14(-)$ & $1.26(0.10)$ & $1.29(0.17)$ \\
H65 shape & $1.14(0.05)$ & $1.18(-)$ & $1.12(-)$ & $1.19(0.12)$ & $1.08(0.05)$ \\
F35\%CA & $63.6(10.7)$ & $63.9(-)$ & $63.6(-)$ & $63.4(7.2)$ & $63.0(2.3)$ \\
F50\%CA & $65.3(10.6)$ & $73.8(-)$ & $73.9(-)$ & $69.2(6.9)$ & $70.1(1.6)$ \\
F65\%CA & $65.0(11.1)$ & $76.9(-)$ & $76.7(-)$ & $72.2(7.7)$ & $72.6(3.2)$ \\
H35\%CA & $63.0(8.7)$ & $74.1(-)$ & $75.0(-)$ & $65.4(10.4)$ & $67.2(15.4)$ \\
H50\%CA & $55.9(9.1)$ & $69.2(-)$ & $69.5(-)$ & $63.3(6.1)$ & $63.6(8.2)$ \\
H65\%CA & $50.4(8.1)$ & $61.6(-)$ & $61.2(-)$ & $60.6(3.7)$ & $59.1(7.2)$ \\
\hline
\end{tabular}

Considering femoral shape ratio averages for the first 3 rows of cells in Table III for females vs. the first 3 rows of cells for males provides 15 analogous locations for female vs. male comparisons, i.e., locality and sides separated. Within the femoral diaphysis, female averages exceed male averages to the same extent that male

Table IV Statistical comparisons of Gombe, Mahale, and Taï diaphyseal shapes $\left(I_{\max } / I_{\min }\right)^{\mathrm{a}}$

\begin{tabular}{|c|c|c|c|c|c|c|c|c|}
\hline \multicolumn{4}{|c|}{ Gombe vs. Mahale vs. Taï females (left) } & \multirow{2}{*}{\multicolumn{2}{|c|}{ post hoc analyses }} & \multicolumn{3}{|c|}{ Mahale vs. Taï females (right) } \\
\hline ROI & $F$ & d.f. & $P$ & & & $t$ & d.f. & $p$ \\
\hline F35 & 2.315 & $2(13)$ & 0.138 & & $\mathrm{~F} 35^{\mathrm{b}}$ & -4.434 & 8.791 & 0.020 \\
\hline $\mathrm{F} 50$ & 2.579 & $2(13)$ & 0.114 & & F50 & -2.256 & 9 & 0.051 \\
\hline F65 & 0.089 & $2(13)$ & 0.915 & & F65 & -1.423 & 9 & 0.188 \\
\hline H35 & 3.572 & $2(14)$ & 0.056 & & H35 & 0.795 & 8 & 0.450 \\
\hline $\mathrm{H} 50$ & 11.268 & $2(14)$ & 0.001 & $\begin{array}{l}\text { Tаї } \neq \text { Gombe }^{c} \\
\text { Taї } \neq \text { Mahale }^{c}\end{array}$ & $\mathrm{H} 50$ & -3.339 & 8 & 0.010 \\
\hline $\mathrm{H} 65^{\mathrm{b}}$ & 5.532 & $2(14)$ & 0.017 & Taï $\neq$ Gombe $^{\mathrm{d}}$ & H65 & -2.269 & 8 & 0.053 \\
\hline \multicolumn{9}{|c|}{ Gombe vs. Mahale vs. Taï males (left) } \\
\hline F35 & 2.189 & $2(5)$ & 0.208 & & & & & \\
\hline $\mathrm{F} 50$ & 1.391 & $2(5)$ & 0.331 & & & & & \\
\hline F65 & 0.021 & $2(5)$ & 0.979 & & & & & \\
\hline $\mathrm{H} 35^{\mathrm{b}}$ & 3.261 & $2(5)$ & 0.124 & & & & & \\
\hline $\mathrm{H} 50^{\mathrm{b}}$ & 4.981 & $2(5)$ & 0.065 & & & & & \\
\hline H65 & 0.409 & $2(5)$ & 0.685 & & & & & \\
\hline
\end{tabular}

$\mathrm{F}=$ femur, $\mathrm{H}=$ humerus; 35 = mid-distal diaphysis, 50 = midshaft; 65 = mid-proximal diaphysis. d.f. $=$ degrees of freedom among groups (within groups).

${ }^{a}$ Results of one-way ANOVAs for left element comparisons using all three groups, and results of t-tests for right element comparisons using only Mahale and Taï individuals. A negative $t$-statistic indicates that on average Taï individuals exceed Mahale individuals in shape ratio at the ROI.

${ }^{\mathrm{b}}$ Failed a Levene test of homogeneity of variances.

${ }^{\mathrm{c}}$ Significant difference according to Bonferroni post hoc analysis.

d Significant difference according to Tamhane's T2 post hoc analysis. 
averages exceed female averages, i.e., 7 vs. 7 with one tie (Table III). Conversely, considering humeral cells, female shape ratio averages exceed male shape ratio averages, i.e., female humeral $I_{\max } / I_{\min }>$ male humeral $I_{\max } / I_{\min }$, at twice as many locations (10 vs. 5; Table III). Qualitative sex differences in shape ratios appear more prevalent in humeral than in femoral diaphyses.

Age-Related Changes in Diaphyses of Females and Males for Pooled Communities

We assessed age-related changes in diaphyseal shapes only for left femoral and humeral diaphyses (Table V; Fig. 1). In pooling females from all communities, we observed a significant negative correlation between age and diaphyseal shape at the humeral midshaft (H50: $r=-0.711, p=0.006$ ) and at the mid-proximal humeral diaphysis (H65: $r=-0.627, p=0.022)$. In other words, diaphyseal shapes in these locations are more circular in older females, i.e., old individual $I_{\max } / I_{\min }<$ young individual $I_{\max } / I_{\min }$. No other ROIs exhibit statistically significant associations in females, nor are any negative associations between age and diaphyseal shape statistically significant among males (Table V). Neither sex exhibits significantly more elliptical diaphyses with increased age.

Pooling all communities, females exhibit a statistically significant negative association between age and \%CA at each femoral and humeral ROI (Table VI; Fig. 2), which is consistent with previous observations from the Gombe chimpanzees alone (Sumner et al. 1989). Pooling all communities, males consistently exhibit negative correlation coefficients, though none is statistically significant. Female mean ages (Table I: femur $=29.4 \mathrm{yr}$, humerus $=29.0 \mathrm{yr}$ ) do not differ substantially from male mean ages (Table I: femur $=28.8$ years, humerus $=32.1 \mathrm{yr}$ ), which suggests that sex differences in \%CA are not sampling artifacts. However, females exhibit a slightly wider range of ages (15-43 yr) than males (19-39 yr).

Table V Pearson correlation results for Gombe, Mahale, and Taï age-related shape change $\left(I_{\max } / I_{\min }\right)^{\mathrm{a}}$

\begin{tabular}{llll}
\hline & $n$ & $r$ & $p$ \\
\hline Females & & & 0.855 \\
F35 & 13 & -0.056 & 0.564 \\
F50 & 13 & 0.177 & 0.230 \\
F65 & 13 & -0.357 & 0.174 \\
H35 & 13 & 0.401 & $0.006^{* *}$ \\
H50 & 13 & -0.711 & $0.022^{*}$ \\
H65 & 13 & -0.627 & 0.310 \\
Males & & & 0.127 \\
F35 & 6 & -0.502 & 0.285 \\
F50 & 6 & -0.693 & 0.733 \\
F65 & 6 & -0.525 & 0.285 \\
H35 & 6 & 0.159 & $0.043^{*}$ \\
H50 & 6 & -0.472 & 0.770 \\
H65 & 6 & & \\
\hline
\end{tabular}

*Significant at $p<0.05$ (two-tailed); **significant at $p<0.01$ (two-tailed). $\mathrm{F}=$ femur, $\mathrm{H}=$ humerus; $35=$ mid-distal diaphysis, $50=$ midshaft; 65 = mid-proximal diaphysis.

${ }^{a}$ Includes only left elements. 


\section{Femur 35}

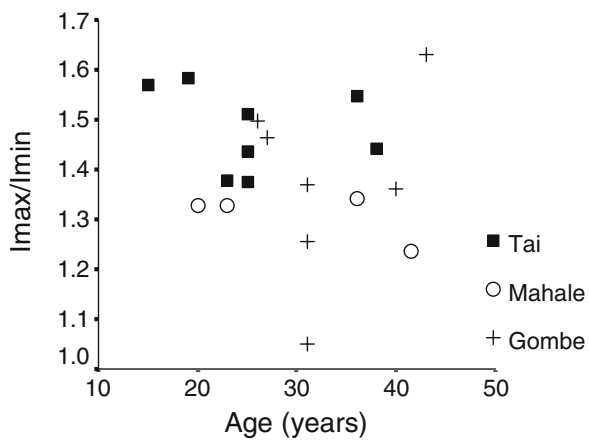

Femur 50

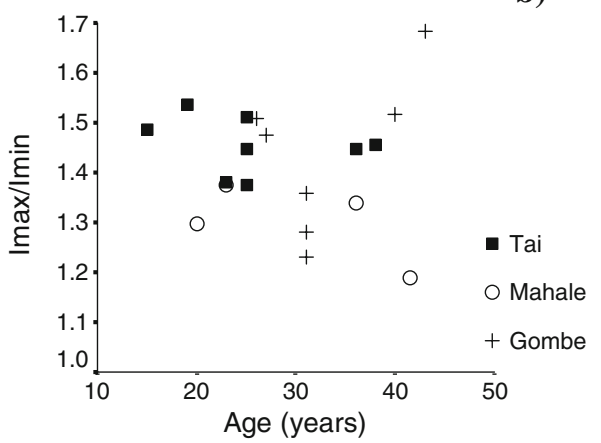

Femur 65

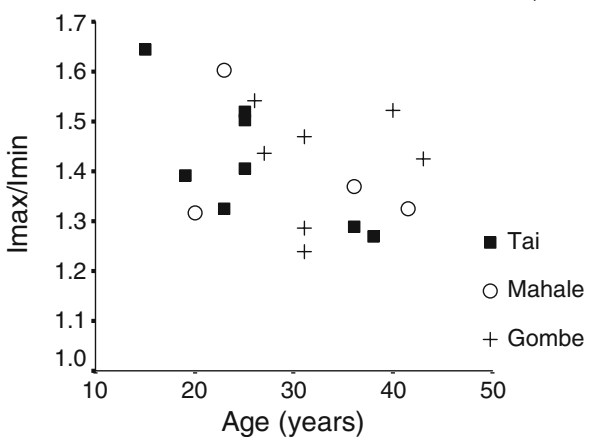

c)
Humerus 35

d)

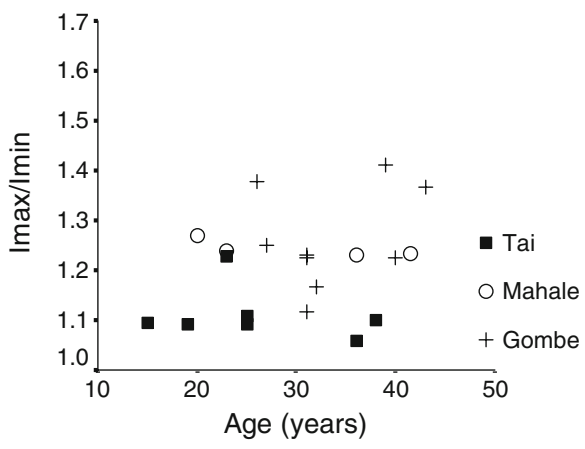

Humerus 50

e)

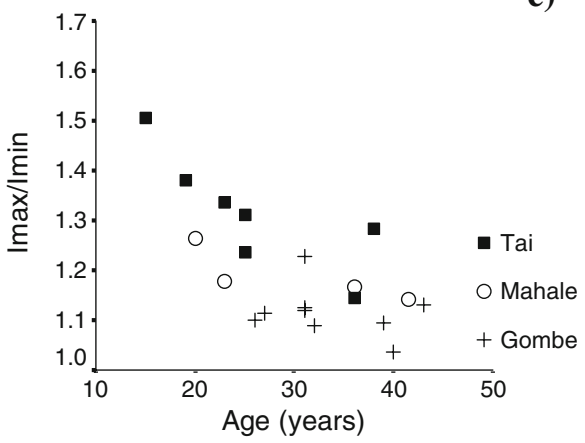

Humerus 65

f)

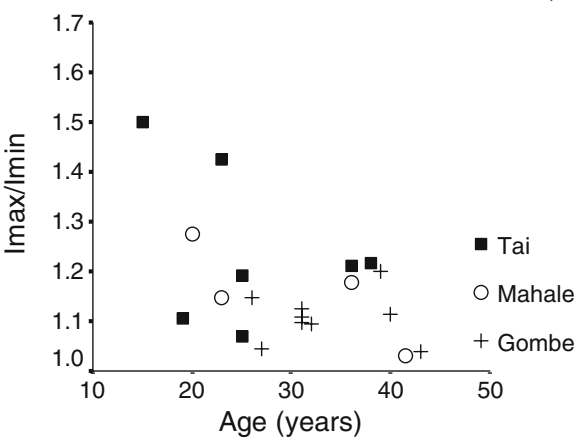

Fig. 1 Shape ratio $\left(I_{\max } / I_{\min }\right)$ plotted versus age at death (yr) for adult chimpanzees from Gombe, Mahale, and Taï Forest. Scatterplots indicate combined female and male samples of left elements only. Cross symbols indicate Gombe individuals, open circles indicate Mahale individuals, and filled squares indicate Taï individuals. Regions of interest include the 35\% femoral diaphysis (a), 50\% femoral diaphysis (b), 65\% femoral diaphysis (c), 35\% humeral diaphysis (d), 50\% humeral diaphysis (e), and 65\% humeral diaphysis (f).

\section{Discussion}

Although communities differ significantly in diaphyseal shape at several locations, the observed differences are not consistently in line with expected patterns based on behavioral observations, e.g., more circular diaphyses expected among more arboreal 
Table VI Pearson correlation results for Gombe, Mahale, and Taï age-related bone loss (\%CA) ${ }^{\mathrm{a}}$

\begin{tabular}{llll}
\hline & $N$ & $r$ & $p$ \\
\hline Females & & & $0.019^{*}$ \\
F35 & 13 & -0.639 & $0.017^{*}$ \\
F50 & 13 & -0.645 & $0.010^{*}$ \\
F65 & 13 & -0.685 & $0.027^{*}$ \\
H35 & 13 & -0.610 & $0.015^{*}$ \\
H50 & 13 & -0.658 & $0.014^{*}$ \\
H65 & 13 & -0.660 & 0.134 \\
Males & & & 0.231 \\
F35 & 6 & -0.684 & 0.302 \\
F50 & 6 & -0.576 & 0.254 \\
F65 & 6 & -0.509 & 0.237 \\
H35 & 7 & -0.499 & 0.243 \\
H50 & 7 & -0.515 & -0.509 \\
H65 & 7 & & \\
\hline
\end{tabular}

*Significant at $p<0.05$ (two-tailed). $\mathrm{F}=$ femur, $\mathrm{H}=$ humerus; $35=$ mid-distal diaphysis, 50 = midshaft; $65=$ mid-proximal diaphysis.

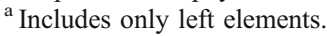

Taï individuals. Studies of cross-sectional properties (Burr et al. 1989; Carlson 2005; Carlson et al. 2006; Schaffler et al. 1985) often infer that locomotion in an arboreal setting favors multidirectional loading in long bone diaphyses relative to locomotion in a terrestrial setting. The assumption appears consistent with the few applicable experimental in vivo bone strain studies of primate locomotion (Demes et al. 2001; Swartz et al. 1989). The expectation that increased circularity of a diaphysis, e.g., more evenly distributed bone mass, is a stable structural solution in the face of multidirectional deformations (Biewener 2003) is intuitive because it lessens the susceptibility of a bone to failure from deformations in any particular direction. However, additional factors beyond behavioral frequency appear relevant to the ultimate shape of long bone diaphyses in our chimpanzee sample.

Habitat characteristics may be one such factor. Taï chimpanzees inhabit a more closed forest characterized by higher rainfall and greater tree density relative to either Gombe or Mahale communities (Table II). Behavioral observations have documented that arboreal locomotion is more common among Taï females $(18.2 \%$ of all locomotor behavior) relative to Gombe or Mahale $(12.0 \%$ of all locomotor behavior) females (Carlson et al. 2006; Doran 1996). Taï males $(14.7 \%$ of all locomotor behavior) engaged in arboreal locomotion nearly twice as much as Gombe or Mahale (8.2\% of all locomotor behavior) males did (Carlson et al. 2006; Doran 1996). However, such habitat characteristics may have additional implications beyond increasing percentage of arboreal locomotion. Taï chimpanzees exhibited slightly lower percentages of quadrupedalism (females $=85.6 \%$, males $=86.6 \%$ ) than Gombe or Mahale (females $=91.5 \%$, males 93.9\%) chimpanzees did (Carlson et al. 2006; Doran 1996). When considering a measure of habitat complexity, i.e., trees per unit area, the habitat of a Taï chimpanzee presumably has more obstacles than those of Gombe or Mahale chimpanzees (Table II). Demes et al. (2006) reported elevated ML external forces of the primate limbs during turning. Carlson and Judex (2007) compared inbred mice that were encouraged to turn with greater frequency over an 

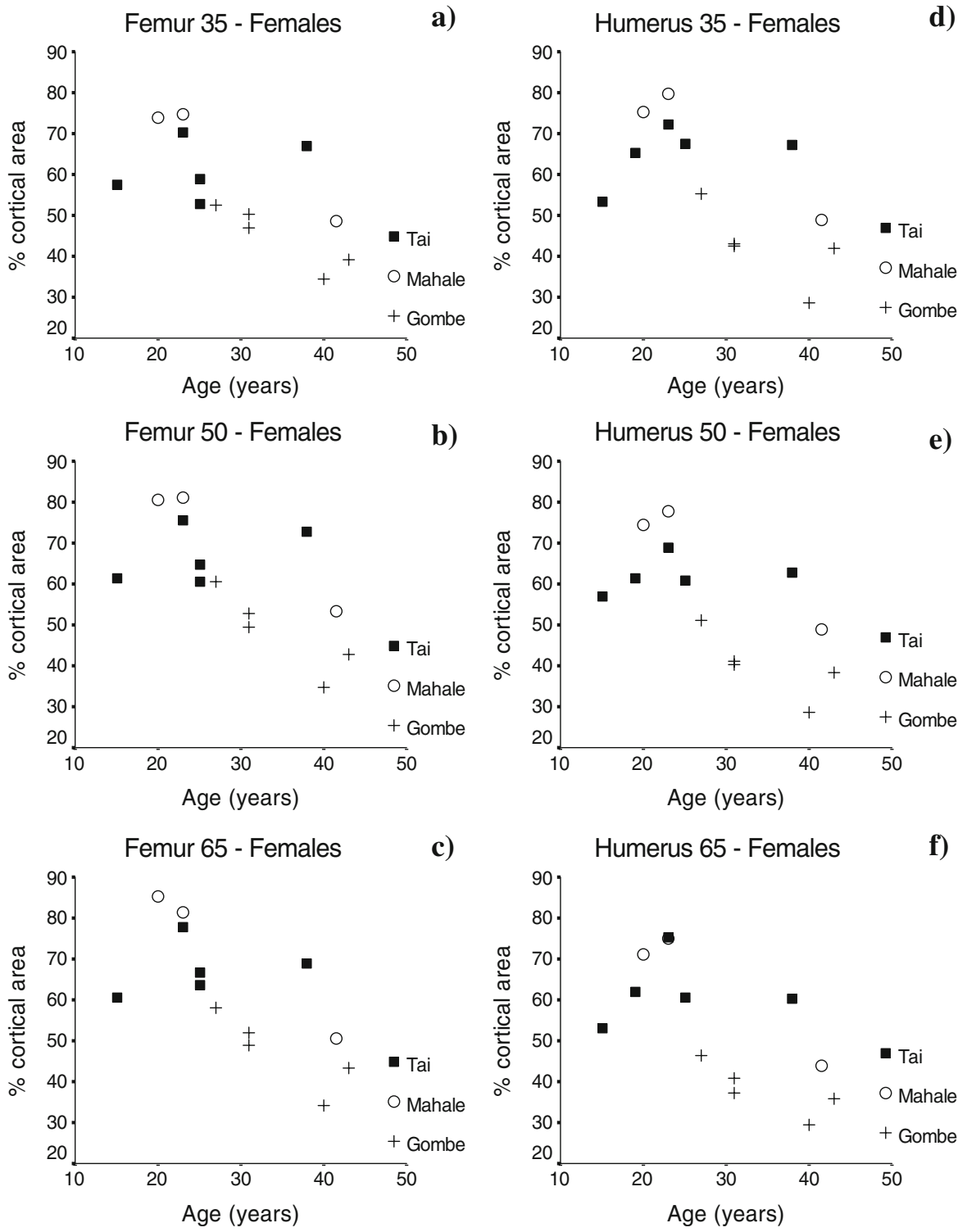

Fig. 2 Percentage cortical area (\%CA) plotted vs. age at death (yr) for adult females from Gombe, Mahale, and Taï Forest. Scatterplots indicate left elements only. Cross symbols indicate Gombe individuals, open circles indicate Mahale individuals, and filled squares indicate Taï individuals. Regions of interest include the $35 \%$ femoral diaphysis (a), 50\% femoral diaphysis (b), 65\% femoral diaphysis (c), $35 \%$ humeral diaphysis (d), 50\% humeral diaphysis (e), and 65\% humeral diaphysis (f).

8-wk period with control individuals and individuals encouraged to increase frequency of linear locomotion. The turning group had significantly more elliptical femoral diaphyses than the other 2 groups (Carlson and Judex 2007). Chimpanzees generally have greater ML than AP rigidity in femoral diaphyses, whereas the tendency is less consistent in their humeral diaphyses (Carlson 2002; 
Carlson et al. 2006). Therefore, more elliptical diaphyses among Taï individuals, at least in the femoral diaphysis, reflect higher ML bending rigidity relative to AP bending rigidity (Carlson et al. 2006; Carlson unpub. data). It is unclear whether the reported frequency difference in quadrupedalism (females: 85.6 vs. 91.5; males 86.6 vs. 93.9) ultimately is trivial to bone functional adaptations. The fact that Tai chimpanzees on average exhibit more elliptical diaphyses than those of other communities at most femoral and humeral ROIs (Table VII) is consistent perhaps with an expectation of higher frequencies of turning behavior.

Mahale has greater elevational change than the other 2 locations. Ruff (1999) noted more elliptical femoral diaphyses in modern human populations from the Great Basin of North America who incorporated more frequent locomotion over rugged, sloped terrain because anteroposteriorly (AP)-oriented loads likely increased relative to the ones experienced during travel over more level terrain. Mahale individuals on average exhibit more circular femoral diaphyses than individuals from the other 2 communities (Table VII). However, because chimpanzees generally have greater ML rigidity than AP rigidity at these femoral ROIs (Carlson 2002; Carlson et al. 2006), an increase in circularity of Mahale femoral diaphyses is consistent with increased AP rigidity relative to ML rigidity. Thus, the same terrain effect observed in human groups appears in the free-ranging chimpanzees as well.

Older adult chimpanzees usually have more circular diaphyses than those of younger adult chimpanzees at a majority of ROIs, particularly at the humeral midshaft and midproximal diaphysis (Table V) or (Fig. 1). Goodall (1986) and Morbeck et al. (2002) described a decline in the frequency of climbing and travel over the course of chimpanzee adulthood at Gombe, i.e., change in activity profile. Though deformations experienced by humeral and femoral diaphyses during most arboreal locomotor modes remain incompletely documented, the available evidence (Demes et al. 1998, 2001; Swartz et al. 1989) is consistent with arboreal locomotion introducing a more variable deformation pattern than terrestrial locomotion. Thus, the behavioral change Goodall (1986) noted should be consistent with younger adults rather than older adults having more circular diaphyses, but such a pattern generally was absent.

Researchers who study cross-sectional properties in human populations often propose that increased circularity of a diaphysis indicates reduced loading

Table VII Ranked shape $\left(I_{\max } / I_{\min }\right)^{\mathrm{a}}$ vs. ranked habitat characteristics

\begin{tabular}{|c|c|c|c|c|}
\hline & Annual rainfall & Ground cover & Elevational range & Slope of terrain ${ }^{\mathrm{b}}$ \\
\hline $\begin{array}{l}\text { Community } \\
\text { ranking }\end{array}$ & $\begin{array}{l}\text { Taï }>\text { Mahale }> \\
\text { Gombe }\end{array}$ & Taï $>$ Mahale $>$ Gombe & $\begin{array}{l}\text { Mahale }>\text { Gombe }> \\
\text { Taï }\end{array}$ & $\begin{array}{l}\text { Gombe }>\text { Mahale }> \\
\text { Taï }\end{array}$ \\
\hline $\begin{array}{l}\text { Femur } \\
\text { shape }\end{array}$ & Female & $\begin{array}{l}\text { 35\%: Taï > Gombe > } \\
\text { Mahale }\end{array}$ & $\begin{array}{l}50 \% \text { : Taï }>\text { Gombe }> \\
\text { Mahale }\end{array}$ & $\begin{array}{l}65 \% \text { : Taï }>\text { Gombe }> \\
\text { Mahale }\end{array}$ \\
\hline ranking & Male & $\begin{array}{l}\text { 35\%: Taï > Gombe > } \\
\text { Mahale }\end{array}$ & $\begin{array}{l}50 \% \text { : Taï }>\text { Gombe }> \\
\text { Mahale }\end{array}$ & $\begin{array}{l}\text { 65\%: Gombe }>\text { Taї }= \\
\text { Mahale }\end{array}$ \\
\hline $\begin{array}{l}\text { Humerus } \\
\text { shape }\end{array}$ & Female & $\begin{array}{l}\text { 35\%: Mahale > Gombe } \\
\text { > Taï }\end{array}$ & $\begin{array}{l}50 \% \text { : Taï }>\text { Mahale }> \\
\text { Gombe }\end{array}$ & $\begin{array}{l}65 \% \text { : Taї }>\text { Mahale }> \\
\text { Gombe }\end{array}$ \\
\hline ranking & Male & $\begin{array}{l}\text { 35\%: Gombe }> \\
\text { Mahale > Taï }\end{array}$ & $\begin{array}{l}50 \%: \text { Taï }>\text { Mahale }> \\
\text { Gombe }\end{array}$ & $\begin{array}{l}\text { 65\%: Taï > Mahale }> \\
\text { Gombe }\end{array}$ \\
\hline
\end{tabular}

\footnotetext{
${ }^{\text {a }}$ Shape ratios reported for left elements only.

${ }^{\mathrm{b}}$ Quantitative data were not available from Taï, but based on the range of elevations, it seems reasonable to characterize terrain at Taï as flatter than at Gombe or Mahale.
} 
conditions, or reduced mobility (Holt 2003; Marchi et al. 2006; Sládek et al. 2006; Stock and Pfeiffer 2001). Clinical studies of subjects with substantially reduced or completely absent mechanical loading of limbs, e.g., as occurs during paraplegia, support the assumption of reduced bone mass (\%CA) and often more circular diaphyses (Dionyssiotis et al. 2007). Consideration of an adult Taï female that we excluded from the sample, Castor, is instructive when considering the alternative. Castor suffered a devastating injury to her right distal femur that essentially eliminated weight-bearing capacity of the right hind limb (Zihlman and Boesch 2005). In comparing femoral midshafts of Castor, the affected right diaphysis $\left(I_{\max } /\right.$ $\left.I_{\min }=1.49\right)$ is less circular than the unaffected left diaphysis $\left(I_{\max } / I_{\min }=1.40\right)$. The unaffected left femur has a \%CA at midshaft nearly twice as high as the affected right femur (66.7 vs. 43.8, respectively). The mid-proximal femoral diaphyses of Castor exhibit similar trends in shape ratios and \%CA (F65: left $I_{\max } / I_{\min }=1.23 \mathrm{vs}$. right $I_{\max } / I_{\min }=1.45$; left $\% \mathrm{CA}=70.8$ vs. right $\% \mathrm{CA}=49.1$ ). Two chimpanzees from Gombe - Gilka and Madam Bee - lost partial use of a forelimb due to poliomyelitis (Morbeck et al. 1999), and each individual exhibited bilateral asymmetries in skeletal dimensions, including reduced bone mass in the affected limb relative to the unaffected limb (Morbeck et al. 1991). In comparing the diaphyseal shapes of Castor, elevated minimum bending rigidities $\left(I_{\min }\right)$ in the unaffected left limb, particularly at the midshaft, are most responsible for the asymmetries (Carlson unpub. data). Though it is not possible to verify through direct observation, it is reasonable to suspect that Castor altered loading conditions of her left hind limb while compensating for the compromised function of her right hind limb. Therefore, Castor demonstrates an opposite shape trend to those reported after loss of function, e.g., weight-bearing, in cases of human paraplegia (Dionyssiotis et al. 2007) or reduced mobility (Holt 2003; Marchi et al. 2006; Sládek et al. 2006; Stock and Pfeiffer 2001).

Decreased \%CA can also reflect reduced functional loading, i.e., reduced activity level. We suggest that linking \%CA and diaphyseal shape change is more helpful to identify reduced functional use of limbs than using either characteristic alone. When a diaphysis exhibits both a more circular shape and reduced \%CA, assuming reduced functional loading, i.e., reduced activity levels, is a safer assumption than when either condition stands alone. In the present sample, older adult chimpanzee humeral and femoral diaphyses from Gombe, Mahale, and Taï often exhibit both greater circularity of diaphyses and reduced \%CA relative to younger individuals. The older chimpanzees likely demonstrated reduced overall activity levels in addition to any behavioral changes in locomotor profiles (Goodall 1986; Morbeck et al. 2002; Figs. 1 and 2).

Mechanotransduction of strain has a genetic component (Robling et al. 2007; Turner et al. 2000; Wergedal et al. 2005; Xiong et al. 2006) that underlies any behaviorally induced change in bone functional adaptations. Pan troglodytes verus exemplified by Taï Forest chimpanzees have the most distinct diaphyses. Western chimpanzees diverged from more closely related central (Pan troglodytes troglodytes) and eastern (P. t. schweinfurthii) chimpanzees ca. $0.84 \mathrm{Ma}$ (Becquet et al. 2007). Analysis of additional chimpanzee populations, e.g., Kibale chimpanzees, may offer further insight into the basis of the morphological distinctiveness of Taï chimpanzees in our sample.

Bridging the gap between field-based and laboratory-based approaches is vital to deepen our understanding of chimpanzee functional morphology, and primate 
functional morphology in general. There is a disconnect between observational studies that provide behavioral frequency information as the unit of comparison and laboratory studies that document functional consequences of the locomotor modes. The same arboreal or terrestrial locomotor mode, e.g., quadrupedalism, may not have equivalent functional implications for individuals in each of the communities. In other words, functionally relevant variation may exist within a defined locomotor mode, e.g., quadrupedalism, that may distinguish among the communities, or even among different individuals. For example, the most detailed methodologies documenting positional behavior among primates (Hunt 1991; Hunt et al. 1996; Thorpe and Crompton 2006) do not distinguish turning behavior within quadrupedalism. Further study of responses to disruptions in a strictly-defined locomotor mode, e.g., perturbations such as directional change, may prove useful to modeling free-ranging behavior (Demes et al. 2006) and by extension will improve inference-building for locomotor behavior and functional morphology of early hominin postcrania.

Future directions in the ongoing collaboration include incorporating other chimpanzee communities, e.g., Kibale National Park, Uganda. Communities that would expand the range of habitats to include more extreme conditions such as dry, open habitats, e.g., Toro-Semliki Wildlife Reserve, Uganda, are equally important to assess. Individuals from such communities could provide valuable opportunities to document morphological variability more thoroughly, which in turn could provide a more thorough opportunity to assess links between cross-sectional properties and ecogeographic factors. Mahale individuals on average exhibit more elliptical left than right humeral diaphyses, but no consistent side asymmetry in femoral diaphyses. In contrast, Taï chimpanzees nearly always exhibit more elliptical right than left femoral and humeral diaphyses. The functional implications of the observed side asymmetries require more study.

\section{Conclusions}

Gombe, Mahale, and Taï chimpanzees exhibit significant differences in diaphyseal shapes, particularly within their humerus. However, observed shape differences do not always correspond to those that would be expected based on behavioral observations. Habitat differences may generate some of the variation among communities. Adult habituated chimpanzees from all 3 communities exhibit age-related bone loss, though it appears less pervasive among Taï individuals than among Gombe or Mahale individuals. Age-related bone loss accompanies age-related shape change at several ROIs, which is consistent with the observation that overall activity levels are reduced as a consequence of aging, at least among individuals in Gombe and Mahale communities. Diaphyseal shape changes, when considered without additional indicators such as $\%$ $\mathrm{CA}$, may not always indicate straightforward changes in activity levels.

Lack of documentation for patterns of bone deformation associated with most locomotor modes in the primate behavioral repertoire limits the ability to infer locomotor repertoires from diaphyseal shapes. Complexities among input factors in mechanotransduction itself warrant caution when using cross-sectional properties to infer behavioral patterns. We encourage devoting additional efforts in the laboratory toward understanding mechanical consequences of a wider array of locomotor 
modes performed by free-ranging primates (Demes et al. 2006). Likewise, observational studies would benefit from embracing results of experimental studies that document currently underappreciated aspects of locomotor behavior profiles of free-ranging primates. Coordinating efforts between field-based and laboratorybased researchers, particularly among primatologists studying our closest living relatives - chimpanzees - would facilitate a multifaceted approach to studying the extent of behavioral influences on bone functional morphology. In turn, modeling locomotor repertoires of early hominins and other extinct ape taxa would become more informative.

Acknowledgments We thank the L. S. B. Leakey Foundation for providing financial support. We thank the Institut für Radiologie, Kantonspital, Winterthur and the Universitätspital, Zürich for access to their CT scanners. Isuf Hoxha and Michael Krupa provided critical assistance with scanning specimens in Zürich. We also thank David Burr, Diane Doran-Sheehy, Jane Goodall, Harumoto Gunji, Kevin Hunt, Tanya Smith, Christoph Zollikofer, and Marcia Ponce de León for their assistance at various times during this research. We thank 2 anonymous reviewers for providing comments that improved the manuscript enormously.

\section{References}

Becquet, C., Patterson, N., Stone, A. C., Przeworksi, M., \& Reich, D. (2007). Genetic structure of chimpanzee populations. PLoS Genetics, 3, e66.

Bhatavadekar, N. B., Daegling, D. J., \& Rapoff, A. J. (2006). Application of an image-based weighted measure of skeletal loading stiffness to great ape mandibles. American Journal of Physical Anthropology, 131, 243-251. doi:10.1002/ajpa.20397.

Biewener, A. A. (2003). Animal locomotion. Oxford: Oxford University Press.

Boesch, C., \& Boesch-Achermann, H. (2000). The Chimpanzees of the Taï Forest - behavioural ecology and evolution. New York: Oxford University Press.

Burr, D. B., Milgrom, C., Fyhrie, D., Forwood, M., Nyska, M., Finestone, A., et al. (1996). In vivo measurement of human tibial strains during vigorous activity. Bone, 18, 405-410. doi:10.1016/8756-3282(96)00028-2.

Burr, D. B., Piotrowski, G., Martin, R. B., \& Cook, P. N. (1982). Femoral mechanics in the lesser bushbaby (Galago senegalensis): Structural adaptations to leaping in primates. The Anatomical Record, 202, 419-429. doi:10.1002/ar.1092020314.

Burr, D. B., Robling, A. G., \& Turner, C. H. (2002). Effects of biomechanical stress on bones in animals. Bone, 30, 781-786. doi:10.1016/S8756-3282(02)00707-X.

Burr, D. B., Ruff, C. B., \& Johnson, C. (1989). Structural adaptations of the femur and humerus to arboreal and terrestrial environments in three species of macaque. American Journal of Physical Anthropology, 79, 357-367. doi:10.1002/ajpa.1330790312.

Carlson, K. J. (2002). Shape and Material Properties of African Pongid Femora and Humeri: Their Relationship to Observed Positional Behaviors. PhD thesis, Indiana University, Bloomington.

Carlson, K. J. (2005). Investigating the form-function interface in African apes - relationships between principal moments of area and positional behaviors in femoral and humeral diaphyses. American Journal of Physical Anthropology, 127, 312-334. doi:10.1002/ajpa.20124.

Carlson, K. J., Demes, B., \& Franz, T. (2005). Mediolateral forces associated with quadrupedal gaits of lemurids. Journal of Zoology (London, England), 266, 261-273. doi:10.1017/S0952836905006874.

Carlson, K. J., Doran-Sheehy, D. M., Hunt, K. D., Nishida, T., Yamanaka, A., \& Boesch, C. (2006). Locomotor behavior and long bone morphology in individual free-ranging chimpanzees. Journal of Human Evolution, 50, 394-404. doi:10.1016/j.jhevol.2005.10.004.

Carlson, K. J., \& Judex, S. (2007). Increased non-linear locomotion alters diaphyseal bone shape. The Journal of Experimental Biology, 210, 3117-3125. doi:10.1242/jeb.006544.

Collins, D. A., \& McGrew, W. C. (1988). Habitats of three groups of chimpanzees (Pan troglodytes) in western Tanzania compared. Journal of Human Evolution, 17, 553-574. doi:10.1016/0047-2484(88)90084-X.

Currey, J. D. (2002). Bones: Structure and Mechanics. Princeton, NJ: Princeton University Press.

Demes, B., Carlson, K. J., \& Franz, T. M. (2006). Cutting corners: The dynamics of turning behaviors in two primate species. The Journal of Experimental Biology, 209, 927-937. doi:10.1242/jeb.02046. 
Demes, B., \& Jungers, W. L. (1989). Functional differentiation of long bones in Lorises. Folia Primatologica, 52, 58-69. Basel.

Demes, B., \& Jungers, W. L. (1993). Long bone cross-sectional dimensions, locomotor adaptations and body size in prosimian primates. Journal of Human Evolution, 25, 57-74. doi:10.1006/jhev.1993.1038.

Demes, B., Jungers, W. L., \& Selpien, K. (1991). Body size, locomotion, and long bone cross-sectional geometry in Indriid primates. American Journal of Physical Anthropology, 86, 537-547. doi:10.1002/ ajpa.1330860409.

Demes, B., Qin, Y., Stern Jr, J. T., Larson, S. G., \& Rubin, C. T. (2001). Patterns of strain in the Macaque tibia during functional activity. American Journal of Physical Anthropology, 116, 257-265. doi:10.1002/ajpa.1122.

Demes, B., Stern, J. T., Hausman, M. R., Larson, S. G., McLeod, K. J., \& Rubin, C. T. (1998). Patterns of strain in the Macaque ulna during functional activity. American Journal of Physical Anthropology, 106, 87-100. doi:10.1002/(SICI)1096-8644(199805)106:1<87::AID-AJPA6>3.0.CO;2-A.

Dionyssiotis, Y., Trovas, G., Galanos, A., Raptou, P., Papaioannou, N., Papagelopoulos, P., et al. (2007). Bone loss and mechanical properties of tibia in spinal cord injured men. Journal of Musculoskeletal \& Neuronal Interactions, 7, 62-68.

Doran, D. M. (1996). The comparative positional behavior of African apes. In W.McGrew, \& T.Nishida (Eds.), Great ape societies (pp. 213-224). Cambridge, UK: Cambridge University Press.

Frost, H. M. (2001). From Wolff's law to the Utah paradigm: Insights about bone physiology and its clinical applications. The Anatomical Record, 263, 398-419. doi:10.1002/ar.1049.

Goodall, J. (1986). The Chimpanzees of Gombe. Cambridge, MA: The Belknap Press of Harvard University Press.

Gross, T. S., Edwards, J. L., McLeod, K. J., \& Rubin, C. T. (1997). Strain gradients correlate with sites of periosteal bone formation. Journal of Bone and Mineral Research, 12, 982-988. doi:10.1359/ jbmr.1997.12.6.982.

Holt, B. (2003). Mobility in upper Paleolithic and Mesolithic Europe: Evidence from the lower limb. American Journal of Physical Anthropology, 122, 200-215. doi:10.1002/ajpa.10256.

Hosaka, K., Matsumoto-Oda, A., Huffman, M. A., \& Kawanaka, K. (2000). Reactions to dead bodies of conspecifics by wild chimpanzees in the Mahale Mountains, Tanzania. Primate Report, 16, 1-15.

Hunt, K. D. (1991). Positional behavior in the Hominoidea. International Journal of Primatology, 12, 95118. doi:10.1007/BF02547576.

Hunt, K. D. (1992). Positional behavior of Pan troglodytes in the Mahale Mountains and Gombe Stream National Parks, Tanzania. American Journal of Physical Anthropology, 87, 83-105. doi:10.1002/ ajpa. 1330870108 .

Hunt, K. D., Cant, J. G. H., Gebo, D. L., Rose, M. D., \& Walker, S. E. (1996). Standardized descriptions of primate locomotor and postural modes. Primates, 37, 363-387. doi:10.1007/BF02381373.

Hunt, K. D., \& McGrew, W. C. (2002). Chimpanzees in the dry habitats of Assirik, Senegal and Semliki wildlife reserve, Uganda. In C. Boesch, G. Hohmann, \& L. F. Marchant (Eds.), Behavioural diversity in Chimpanzees and Bonobos (pp. 35-51). Cambridge, UK: Cambridge University Press.

Hurwitz, D. E., Sumner, D. R., Andriacchi, T. P., \& Sugar, D. A. (1998). Dynamic knee loads during gait predict proximal tibial bone distribution. Journal of Biomechanics, 31, 423-430. doi:10.1016/S00219290(98)00028-1.

Judex, S., Gross, T. S., \& Zernicke, R. F. (1997). Strain gradients correlation with sites of exercise-induced bone-forming surfaces in the adult skeleton. Journal of Bone and Mineral Research, 12, 1737-1745. doi:10.1359/jbmr.1997.12.10.1737.

Jungers, W. L., Burr, D. B., \& Cole, M. S. (1998). Body size and scaling of long bone geometry, bone strength, and positional behavior in cercopithecoid primates. In E. Strasser, J. Fleagle, A. Rosenberger, \& H. M. McHenry (Eds.), Primate locomotion - recent advances (pp. 309-330). New York: Plenum Press.

Lieberman, D. E., Polk, J. D., \& Demes, B. (2004). Predicting long bone loading from cross-sectional geometry. American Journal of Physical Anthropology, 123, 156-171. doi:10.1002/ajpa.10316.

Marchi, D., Sparacello, V. S., Holt, B. M., \& Formicola, V. (2006). Biomechanical approach to the reconstruction of activity patterns in Neolithic Western Liguria, Italy. American Journal of Physical Anthropology, 131, 447-455. doi:10.1002/ajpa.20449.

Martin, C. (1991). The rainforests of west Africa: Ecology, threats, conservation. Basel: Birkhäuser.

Martin, R. B., Burr, D. B., \& Sharkey, N. A. (1998). Skeletal Tissue Mechanics. New York: Springer-Verlag.

McGraw, W. S. (1998). Comparative locomotion and habitat use of six monkeys in the Taï Forest, Ivory Coast. American Journal of Physical Anthropology, 105, 493-510. doi:10.1002/(SICI)1096-8644 (199804)105:4<493::AID-AJPA7>3.0.CO;2-P. 
Moisio, K. C., Hurwitz, D. E., \& Sumner, D. R. (2004). Dynamic loads are determinants of peak bone mass. Journal of Orthopaedic Research, 22, 339-345. doi:10.1016/j.orthres.2003.08.002.

Moore, J. (1996). Savanna chimpanzees, referential models and the last common ancestor. In W. McGrew, \& T. Nishida (Eds.), Great ape societies (pp. 275-292). Cambridge, UK: Cambridge University Press.

Morbeck, M. E. (1999). Life history of Gombe chimpanzees: The inside view from the skeleton. In S. C. Strum, D. G. Lindburg, \& D. Hamburg (Eds.), The new physical anthropology: Science, humanism, and critical reflection (pp. 18-31). Upper Saddle River, NJ: Prentice-Hall.

Morbeck, M. E., Galloway, A., \& Sumner, D. R. (2002). Getting old at Gombe: Skeletal aging in wildranging chimpanzees. In J. Erwin, \& P. R. Hof (Eds.), Aging in nonhuman primates. interdisciplinary topics in gerontology (vol. 31, (pp. 48-62)). Basel/New York: Karger.

Morbeck, M. E., Zihlman, A. L., Sumner, D. R., \& Galloway, A. (1991). Poliomyelitis and skeletal asymmetry in Gombe chimpanzees. Primates, 32, 77-91. doi:10.1007/BF02381602.

Nagurka, M. L., \& Hayes, W. C. (1980). An interactive graphics package for calculating cross-sectional properties of complex shapes. Journal of Biomechanics, 13, 59-64. doi:10.1016/0021-9290(80)90008-1.

Nishida, T. (1990). The chimpanzees of the mahale mountains - sexual and life history strategies. Tokyo: University of Tokyo Press.

Ohman, J. C. (1993). Cross-sectional Geometric Properties from Biplanar Radiographs and Computed Tomography: Functional Application to the Humerus and Femur in Hominoids. PhD thesis, Kent State University, Kent, OH, USA.

Pearson, O. M., \& Lieberman, D. E. (2004). The aging of Wolff's "law": Ontogeny and responses to mechanical loading in cortical bone. Yearbook of Physical Anthropology, 47, 63-99. doi:10.1002/ajpa.20155.

Polk, J. D., Demes, B., Jungers, W. L., Biknevicius, A. R., Heinrich, R. E., \& Runestad, J. A. (2000). A comparison of primate, carnivoran and rodent limb bone cross-sectional properties: Are primates really unique. Journal of Human Evolution, 39, 297-325. doi:10.1006/jhev.2000.0420.

Pontzer, H., \& Wrangham, R. W. (2004). Climbing and the daily energy cost of locomotion in wild chimpanzees: Implications for hominoid locomotor evolution. Journal of Human Evolution, 46, 317335. doi:10.1016/j.jhevol.2003.12.006.

Prost, J. (1965). A definitional system for the classification of primate locomotion. American Anthropologist, 67, 1198-1214. doi:10.1525/aa.1965.67.5.02a00060.

Robling, A. G., Warden, S. J., Shultz, K. L., Beamer, W. G., \& Turner, C. H. (2007). Genetic effects on bone mechanotransduction in congenic mice harboring bone size and strength quantitative trait loci. Journal of Bone and Mineral Research, 22, 984-991. doi:10.1359/jbmr.070327.

Rubin, C., Judex, S., \& Qin, Y.-X. (2006). Low-level mechanical signals and their potential as a nonpharmacological intervention for osteoporosis. Age and Ageing, 35, 32-36. doi:10.1093/ageing/afl082.

Ruff, C. B. (1987). Structural allometry of the femur and tibia in Hominoidea and Macaca. Folia Primatologica, 48, 9-49.

Ruff, C. B. (1989). New approaches to structural evolution of limb bones in primates. Folia Primatologica, 53, 142-159. Basel.

Ruff, C. B. (1999). Skeletal structure and behavioral patterns of prehistoric Great Basin populations. In B. E. Hemphill, \& C. S. Larsen (Eds.), Prehistoric lifeways in the great basin wetlands: bioarchaeological reconstruction and interpretation (pp. 290-320). Salt Lake City: University of Utah Press.

Ruff, C. B. (2002). Long bone articular and diaphyseal structure in Old World monkeys and apes. I: Locomotor effects. American Journal of Physical Anthropology, 119, 305-342. doi:10.1002/ajpa.10117.

Ruff, C. B., Holt, B., \& Trinkaus, E. (2006). Who's afraid of the big bad Wolff?: "Wolff's law" and bone functional adaptation. American Journal of Physical Anthropology, 129, 484-498. doi:10.1002/ ajpa. 20371.

Ruff, C. B., \& Runestad, J. A. (1992). Primate limb bone structural adaptations. Annual Review of Anthropology, 21, 407-433. doi:10.1146/annurev.an.21.100192.002203.

Schaffler, M. B., Burr, D. B., Jungers, W. L., \& Ruff, C. B. (1985). Structural and mechanical indicators of limb specialization in primates. Folia Primatologica, 45, 61-75. Basel.

Sládek, V., Berner, M., \& Sailer, R. (2006). Mobility in central European late eneolithic and early bronze age: Femoral cross-sectional geometry. American Journal of Physical Anthropology, 130, 320-332. doi:10.1002/ajpa.20372.

Stock, J., \& Pfeiffer, S. (2001). Linking structural variability in long bone diaphyses to habitual behaviors: Foragers from southern African Later Stone Age and Andaman Islands. American Journal of Physical Anthropology, 115, 337-348. doi:10.1002/ajpa.1090.

Sumner, D. R., \& Andriacchi, T. P. (1996). Adaptation to differential loading: Comparison of growthrelated changes in cross-sectional properties of the human femur and humerus. Bone, 19, 121-126. doi:10.1016/8756-3282(96)00166-4. 
Sumner, D. R., Morbeck, M. E., \& Lobick, J. J. (1989). Apparent age-related bone loss among adult female Gombe chimpanzees. American Journal of Physical Anthropology, 79, 225-234. doi:10.1002/ ajpa.1330790210.

Swartz, S. M., Bertram, J. E. A., \& Biewener, A. A. (1989). Telemetered in vivo strain analysis of locomotor mechanics of brachiating gibbons. Nature, 342, 270-272. doi:10.1038/342270a0.

Terranova, C. J. (1995a). Functional morphology of leaping behaviors in galagids: Associations between loading, limb use and diaphyseal geometry. In L. Atterman, M. K. Izard, \& G. A. Doyle (Eds.), Creatures of the dark: The nocturnal prosimians (pp. 473-493). New York: Plenum Press.

Terranova, C. J. (1995b). Leaping behaviors and the functional morphology of strepsirhine primate long bones. Folia Primatologica, 65, 181-201 Basel.

Thorpe, S. K. S., \& Crompton, R. H. (2006). Orangutan positional behavior and the nature of arboreal locomotion in Hominoidea. American Journal of Physical Anthropology, 131, 384-401. doi:10.1002/ ajpa. 20422.

Turner, C. H. (1998). Three rules for bone adaptation to mechanical stimuli. Bone, 23, 399-407. doi:10.1016/S8756-3282(98)00118-5.

Turner, C. H., Hsieh, Y. F., Muller, R., Bouxsein, M. L., Baylink, D. J., Rosen, C. J., et al. (2000). Genetic regulation of cortical and trabecular bone strength and microstructure in inbred strains of mice. Journal of Bone and Mineral Research, 15, 1126-1131. doi:10.1359/jbmr.2000.15.6.1126.

Umemura, Y., Ishiko, T., Yamauchi, T., Kurono, M., \& Mashiko, S. (1997). Five jumps per day increase bone mass and breaking force in rats. Journal of Bone and Mineral Research, 12, 1480-1485. doi:10.1359/jbmr.1997.12.9.1480.

Wergedal, J. E., Sheng, M. H., Ackert-Bicknell, C. L., Beamer, W. G., \& Baylink, D. J. (2005). Genetic variation in femur extrinsic strength in 29 different inbred strains of mice is dependent on variations in femur cross-sectional geometry and bone density. Bone, 36, 111-122. doi:10.1016/j. bone.2004.09.012.

Xiong, D. H., Shen, H., Xiao, P., Guo, Y. F., Long, J. R., Zhao, L. J., et al. (2006). Genome-wide scan identified QTLs underlying femoral neck cross-sectional geometry that are novel studied risk factors of osteoporosis. Journal of Bone and Mineral Research, 21, 424-437. doi:10.1359/JBMR.051202.

Yamanaka, A., Gunji, H., \& Ishida, H. (2005). Curvature, length, and cross-sectional Geometry of the femur and humerus in anthropoid primates. American Journal of Physical Anthropology, 127, 46-57. doi:10.1002/ajpa.10439.

Zihlman, A. (1996). Reconstructions reconsidered: chimpanzee models and human evolution. In W. McGrew, \& T. Nishida (Eds.), Great ape societies (pp. 293-304). Cambridge, UK: Cambridge University Press.

Zihlman, A., \& Boesch, C. (2005). Skeletal pathologies in wild chimpanzees from Taï National Forest, Côte d'Ivoire. American Journal of Physical Anthropology, (Suppl. 40), 230.

Zollikofer, C. P. E., Ponce de León, M. S., Martin, R. D., \& Stucki, P. (1995). Neanderthal computer skulls. Nature, 375, 283-285. doi:10.1038/375283b0. 